\title{
Medication omissions in the first 48 hours after admission: failure in prescribed medicines reaching in-patients in paediatrics wards at the University Teaching Hospitals, Children's Hospital in Lusaka, Zambia
}

\section{Martin Kampamba ${ }^{1 *}$, Steven Mulolo ${ }^{1}$, Margaret Phiri ${ }^{2}$, Martha Chibale Chulu ${ }^{3}$, Webrod Mufwambi ${ }^{1}$, Steward Mudenda ${ }^{1}$, Michelo Banda ${ }^{1}$, Christabel Nang'andu Hikaambo ${ }^{1}$}

\author{
${ }^{1}$ Department of Pharmacy, School of Health Sciences, University of Zambia, Lusaka, Zambia \\ ${ }^{2}$ Department of Pharmacy, School of Medicine and Health Sciences, Mulungushi University, Kabwe, Zambia \\ ${ }^{3}$ Department of Pharmacy, School of Health Sciences, Levy Mwanawasa Medical University, Lusaka, Zambia
}

Received: 19 October 2021

Accepted: 10 November 2021

\section{*Correspondence:}

Dr. Martin Kampamba,

Email: martin.kampamba@unza.zm

Copyright: $\odot$ the author(s), publisher and licensee Medip Academy. This is an open-access article distributed under the terms of the Creative Commons Attribution Non-Commercial License, which permits unrestricted non-commercial

\begin{abstract}
Background: The first few days of in-patient care are possibly the most significant in a patient's recovery and any omitted medications during this period may harm the patient or increase their hospital length of stay. Therefore, our study aimed at assessing the frequency of medication administration omission errors and their reasons for the omission in the paediatric wards after admission at University Teaching Children's Hospital.

Methods: This was a descriptive study in which 259 patient files and drug charts were reviewed. Admission prescription charts were studied in detail over a period of four weeks and all drugs prescribed but then not given in the first 48 hours were recorded as omitted medications, along with the reason given for their omission.

Results: From the 259 drug charts, a total of 1598 doses of drugs were ordered within 48 hours of admission. However, from this, only a total of 1132 doses were administered with the remaining 466 doses omitted, which accounted for a frequency of $29.2 \%$. When the frequency of medication omission errors was compared, parenteral drugs $(70.8 \%$ vs. $25.3 \%$, $[\mathrm{p}=0.0001])$, afternoon shift $(48.5 \%$ vs. $15.8 \%$, $[\mathrm{p}=0.0001])$, and anti-infective medications $(69.1 \%$ vs. $39.4 \%$, [ $\mathrm{p}=0.0001])$ were found to be the most frequently omitted medications. There were also considerably more medication omissions in patients prescribed with more medications (median number: 4, I QR [2, 6] vs. median number: 2 , IQR $[2,4],[p=0.0 .001])$. The most common reason for the omission was medication unavailability $(89.3 \%)$, followed by work overload $(71.4 \%)$, and the patient is off the ward $(71.4 \%)$.

Conclusions: This study revealed that medication omissions are a continuing problem and this may result in increased morbidity and mortality rates. There is a need to put in place specific strategies to reduce this problem.
\end{abstract}

Keywords: Medication omissions, Administration errors, Medication errors, Paediatrics

\section{INTRODUCTION}

Drug administration omission errors involve the failure of a drug to be administered for a variety of reasons and are among the most common medication administration errors. ${ }^{1-3}$ Omission errors fall among other medication errors which pose a global problem in both developed and developing countries. ${ }^{4,5}$ Such errors cause patients to suffer increased financial burden, unnecessary discomfort and prolonged hospitalization, morbidity and mortality, rendering these errors clinically significant. ${ }^{6,7}$ Omission of drugs such as antimicrobial agents has the potential to cause patient harm through increased risk of treatment failure and development of more resistant strains of pathogenic microorganisms. ${ }^{8,9}$

The earliest days of inpatient care are perhaps of the utmost significance in a patient's recovery; therefore, any 
omission of medications during this period has the possibility of increasing morbidity and mortality. ${ }^{10}$ An audit showed that $20 \%$ of the prescribed medication in the first 48 hours did not reach the patients and this affected $17 \%$ of the in-patients. ${ }^{11}$ Some studies have shown that the pediatric population experiences potentially harmful medication administration errors about three times more often than adults, thereby putting the pediatric population at a greater risk than adults. ${ }^{12,13}$ Some studies indicate a tenfold higher rate of these medication errors in children. ${ }^{14,15}$

The reasons, as well as factors associated with medication omission errors, have been widely reported by other studies. ${ }^{16,17}$ An audit reported that unavailability of medication, as well as nil by mouth, were the foremost reasons for medication omission. ${ }^{11}$ Other reasons for medication omissions that have been reported include work overload, refusal to take medication, patient inability to take medication and patients not having intravenous (IV) access to administer IV medications. ${ }^{17-19}$

A study on medication administration omission errors have been conducted in the adult population in Zambia. ${ }^{16}$ However, there have not been any published studies that have quantified medication omission errors in the 48 hours after admission in paediatric patients. This study, therefore, assessed the frequency and reasons of medication omission after admission in paediatrics wards at University Teaching Hospitals, Children's Hospital.

\section{METHODS}

\section{Study design}

This was a cross-sectional study done at University Children's Hospital wards where the files and drug charts of paediatric patients admitted within 48 hours were used as a source of data.

\section{Study population}

The study included paediatric patients aged below 18 years admitted to the wards and nurses who were in charge of administering medications to in-patients.

\section{Sample size determination and sampling technique}

We used the prevalence formula to calculate the sample size based on the study that was conducted in subSaharan Africa. ${ }^{20} \mathrm{n}=\mathrm{Z}^{2} \mathrm{P}(100-\mathrm{P}) / \mathrm{e}^{2}$. Sample size was calculated using Cochrane's formula at $95 \%$ confidence level, margin of error $(e)=5 \%$ and $z=1.96$. A sample size of 259 was determined. Therefore, a total of 259 patients' files were used in this study. All medical files with complete patient, drug and disease information were purposively sampled. A total of 28 nurses were conveniently sampled because they are responsible for medication administration in the sampled study site.

\section{Data collection}

Questionnaires with open and closed-ended questions were administered to nurses who were available to administer medications to paediatric patients within the first 48 hours of admission. The questionnaires were used to determine the reasons for medication omission errors. To detect medication omission administration errors, two techniques were employed: the direct observation method and the review of patient drug charts and files. The observation method was used in the morning, afternoon, and evening on nurses who were selected by convenience sampling. This approach was used because it gives more efficient, objective, and reliable results. At the start of the observation period, each nurse was given written consent to participate in the study.

Drug charts and files of all inpatients in the study were prospectively screened for medication omission errors. The screening confirmed the suitability of prescriptions on the medication chart if they were matching to the prescriptions in the medical notes, and examined whether the prescription charts were imprecise. Each treatment chart was count up only once, irrespective of how many times it was seen. Doses that were suspended according to policies calling for withholding of medication doses such as nothing by mouth before surgery, hold until renal and liver function improve were not counted as opportunities for omission errors.

\section{Data analysis}

Data obtained using questionnaires were coded and analyzed using Microsoft excel and statistical package for social sciences (IBM® ${ }^{\circ} \quad$ SPSS $\left.®\right)$ version 22.0, respectively. Data was then expressed in form of frequencies and percentages. Microsoft Excel was used to generate bar charts. To compare the medication omission frequencies of categorical variables, the Pearson-Chisquare test was used. To identify the difference between two medians of continuous variables, we used the Wilcoxon-Mann Whitney rank-sum test and a $\mathrm{p}$ value $<0.05$ was considered statistically significant.

\section{RESULTS}

\section{Demographic information}

A total number of 259 inpatients were seen over a period of four weeks from different wards. The patient's mean age was found to be 6.02 years with the standard deviation being \pm 4 . A total of 28 nurses were enrolled in this study and the majority $15(53.6 \%)$ were females. The mean age of nurses was $27(\mathrm{SD} \pm 4)$ and $24(85.7 \%)$ of the respondents were registered, nurses. Most of the participants $14(50 \%)$ had working experience of more than 5 years, and the nurse-to-patient ratio was 1 to greater than 30 . 
Table 1: Baseline characteristics of nurses who took part in the study $(n=28)$.

\begin{tabular}{|lll|}
\hline Variable & Frequency & Percentage \\
\hline Gender & & \\
\hline Male & 13 & 46.4 \\
\hline Female & 15 & 53.6 \\
\hline Age & Mean \pm SD & $27 \pm 4$ \\
\hline Qualifications & \\
\hline Registered nurse & 24 & 85.7 \\
\hline Enrolled nurse & 4 & 14.3 \\
\hline Working experience in years & \\
\hline $1<$ & 5 & 17.9 \\
\hline $2-4$ & 9 & 32.1 \\
\hline $5>$ & 14 & 50 \\
\hline Nurse to patient ratio & \\
\hline 1 & $>30$ & 100 \\
\hline
\end{tabular}

\section{The frequency of medication omission errors}

From the total number of 1598 doses prescribed to 259 inpatients in the first 48 hours after admission over a period of 4 weeks, 466 doses did not reach the patient, representing the frequency of $29.2 \%$ of medication omission errors as shown in Figure 1.

\section{Comparisons of frequency of medication omissions}

When the class of drug was compared, there was a high proportion of anti-infective drugs among the omitted medications than those not omitted $(69.1 \%$ vs. $39.4 \%$ $[\mathrm{p}=0.0001])$. Additionally, when the route of administration was also compared, there was a high proportion of parenteral drugs among the omitted medications than the medication not omitted $(70.8 \%$ vs. $25.3 \%$, [ $p=0.0001]$. Furthermore, when there was a comparison in terms of work shift, the afternoon shift had a high proportion of the omitted medications as compared to the medications not omitted $(48.5 \%$ vs. $15.8 \%$, $[\mathrm{p}=0.0001]$. When the number of prescribed medications was compared, there were considerably more medication omissions in patients prescribed more medications than in those with fewer medications (median number: 4, IQR [2,6] vs. median number: 2 , IQR $[2,4],[\mathrm{p}=0.0 .001])$ as shown in Table 2.

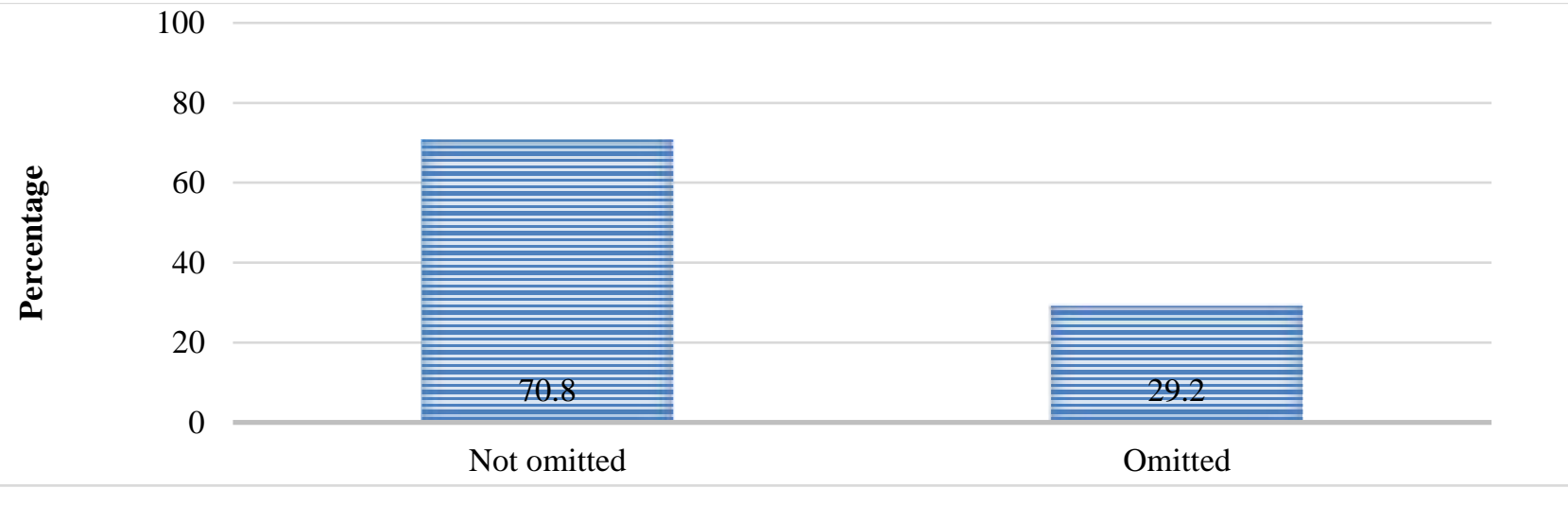

Figure 1: Frequency of medication omissions.

Table 2: Comparisons of frequency of medication omission by category $(n=1598)$.

\begin{tabular}{|llll|}
\hline & Not omitted (n=1132) & Omitted (n=466) & P value \\
\hline Class of drug & $\mathbf{N}(\mathbf{\%})$ & & 0.0001 \\
\hline Anti-infective & $446(39.4)$ & $322(69.1)$ & \\
\hline Blood and nutrition & $452(39.9)$ & $48(10.3)$ & 0.0001 \\
\hline Analgesia & $196(17.3)$ & $32(6.9)$ & 0.0001 \\
\hline Others & $38(3.4)$ & $64(13.7)$ & \\
\hline Route of administration & & $136(29.2)$ & \\
\hline Oral & $846(74.7)$ & $330(70.8)$ & \\
\hline Parenteral & $286(25.3)$ & $118(25.3)$ & \\
\hline Work shifts & & $226(48.5)$ & $122(26.2)$ \\
\hline Morning & $588(51.9)$ & & 0.0001 \\
\hline Afternoon & $178(15.8)$ & $4(2.6)$ & \\
\hline Evening & $366(32.3)$ & & \\
\hline & Median (IQR) & \\
\hline Number of medication & $2(2.4)$ & & \\
\hline
\end{tabular}


Table 3: Omitted class of drugs by British Nation Formulary (BNF) category.

\begin{tabular}{|lll|}
\hline Class & Frequency & $\begin{array}{l}\text { Percentage } \\
(\%)\end{array}$ \\
\hline Anti-infective & 768 & 48.0 \\
\hline $\begin{array}{l}\text { Blood and } \\
\text { nutrition }\end{array}$ & 500 & 31.3 \\
\hline Analgesia & 228 & 14.3 \\
\hline Others & 102 & 6.4 \\
\hline
\end{tabular}

Others (central nervous system, Cardiovascular, Endocrine, Musculoskeletal).

\section{Commonly omitted classes of drugs}

The most common classes of drugs that were prescribed but did not reach the patients were anti-infective 768 (48\%) followed by blood and nutrition 500 (31.3\%).

\section{Reasons medication omission errors}

Figure 2 shows the reason why medications were not administered to the patients by the 28 nurses who enrolled in the study. The study established the common reasons for medication omission were medication unavailability $(89.3 \%)$, followed by work overload $(71.4 \%)$ and patients being off the ward $(71.4 \%)$.

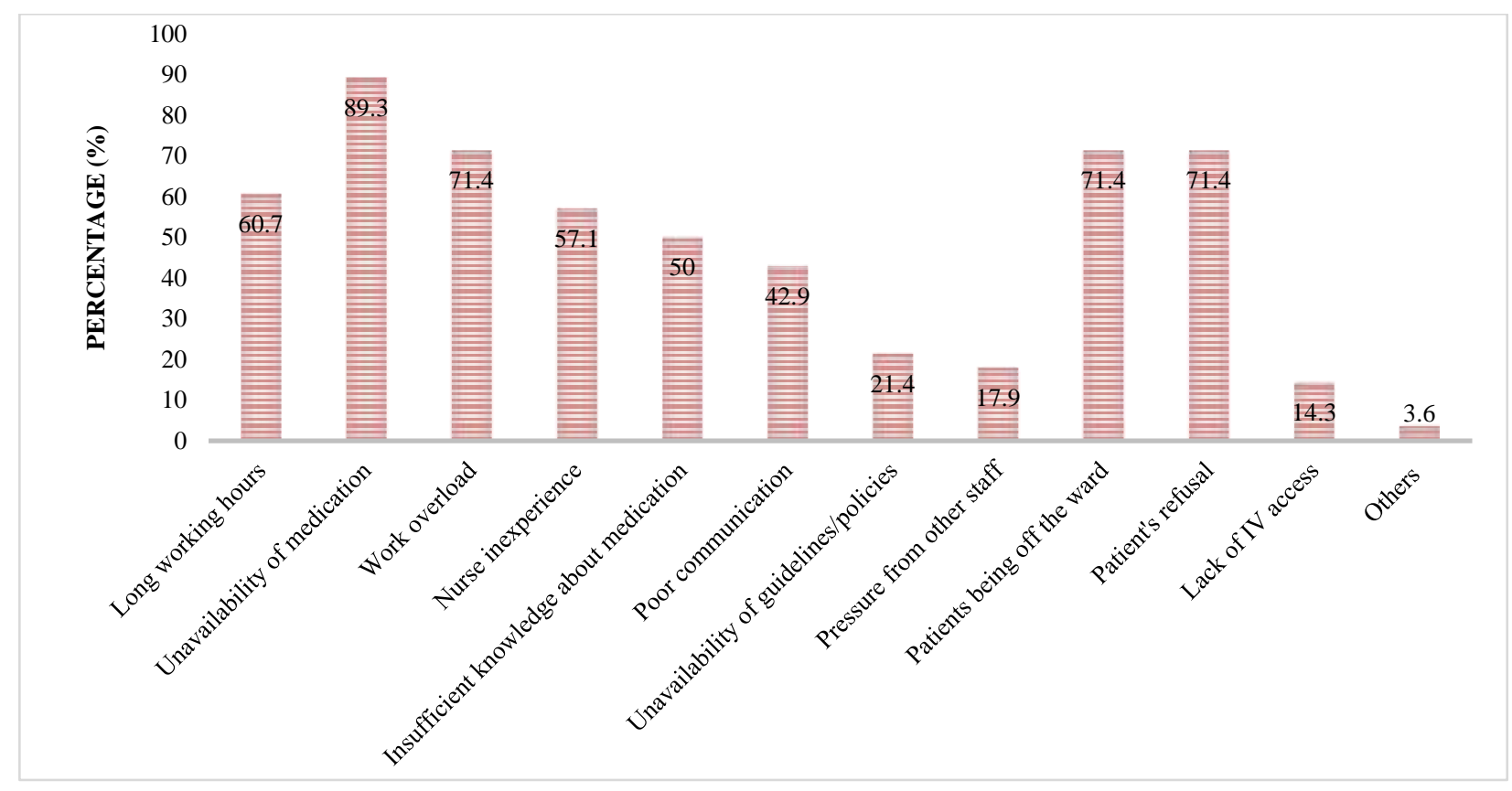

Figure 2: Reasons for medication omissions.

\section{DISCUSSION}

Failure to administer prescribed medications to in-patients has the potential to significantly harm the patient, delay the resolution of the pathology and prolong the length of hospitalization. ${ }^{11}$ Therefore, this study was aimed at assessing the frequency of medication omission errors and the reasons for medication omission in paediatrics wards after admission at University Teaching Children's Hospital. To the best of our knowledge, this is the second study that has measured medication omissions in the first 48 hours after admission and it was difficult to compare our findings to other studies because many studies measured the frequency of medication omission throughout hospital length of stay.

This study established that the frequency of medication omission in paediatric in-patients after admission was $29.2 \%$. This was higher than the $20 \%$ frequency of medication omission found by a similar study that also investigated medication omission within 48 hours of admission. ${ }^{11}$ The frequency in our study could have been higher because Green et al looked at medication omission per 'patients rather than per 'doses'. Studies have shown that the medication omission error rates may vary according to the methodology used to calculate administration errors. ${ }^{21}$ However, the rates of medication omission per patient ranged from $26 \%$ to $79 \%$ and our finding falls within the range.

When we compared the frequency of medication omission, there were a significant proportion of antiinfective drugs that were omitted rather than not omitted. This finding was highlighted by other studies. ${ }^{16,20}$ Additionally, there was a high proportion of parenteral drugs among the omitted medication. Furthermore, regarding work shift comparisons, there was a high proportion of afternoon shifts among the omitted medications. This finding is in contrast to what was reported in another study where the frequency of medication omissions occurred more in the morning shift. ${ }^{17}$ When the number of prescribed medications was 
compared, there were considerably more medication omissions in patients prescribed more medications. Our finding was similar to that of previous studies. ${ }^{16,22,23}$

Furthermore, the most common reason for medication omission errors as reported by nurses was the unavailability of medication $(89.3 \%)$, followed by work overload $(71.4 \%)$ and patients being off the ward $(71.4 \%)$. These findings were similar to a study that cited the unavailability of medication on the ward as the main reason for medication omission. ${ }^{11,24}$ When the prescribed or alternative drugs are not available, nurses may not have an option but to omit those drugs. The workload highlighted in this study as one of the main reasons for medication omission is supported by the high patient-tonurse ratio reported in previous studies. ${ }^{16,25,26}$ Other studies have also reported workload as the major reason for medication omission errors. ${ }^{21,27}$ Nurses may become overwhelmed by work causing them to miss the administration of certain medicines. Work overload may also make nurses fatigued to an extent where they may omit the administration of some drugs.

This study found that the highest number of drug omissions was observed in the anti-infective class (48.0\%), blood and nutrition class (31.3\%) and analgesics $(14.3 \%)$. The omission of anti-infective at such a high rate agrees with other studies in which anti-infective (52\%) were the most commonly missed group of medications. ${ }^{16,20,28,29}$ The omission of drugs used to treat infectious diseases shows that the burden of infectious diseases in Zambia and other countries is high. On the other hand, a study done by Shandilya at Wales's hospital in the United Kingdom showed that the most commonly omitted classes of medication were those for gastroenterology $(17.5 \%)$ followed by those used for cardiovascular $(16.8 \%)$ disorders. The differences in the classes of medication omitted could be because of differences in geographical location coupled with ethnicity, which significantly affect disease pattern distribution. Besides, this may entail that there may be a difference in the distribution of common diseases experienced across the world.

\section{Limitations of the study}

There was the possibility of the Hawthorne effect being at play on the part of the nurses due to direct observation, which is the gold standard for this type of study as it gives more efficient, objective, and reliable results than spontaneous reporting. ${ }^{30}$ This study was conducted in one hospital which limits the generalization of the findings.

\section{CONCLUSION}

This study established a high prevalence (29.2\%) for medication omission administration errors at UTH Children's Hospital. Unavailability of medication was the highest contributing factor to medication omission administration errors. There is a need to control medication omission errors so that pediatric patient treatment outcomes are improved.

\section{ACKNOWLEDGEMENTS}

The authors would like to thank all the participants in this study and are grateful to the University of Zambia e-library for providing access to most of the articles used in this publication.

\section{Funding: No funding sources Conflict of interest: None declared \\ Ethical approval: The study was approved by the Institutional Ethics Committee}

\section{REFERENCES}

1. Coleman JJ, McDowell SE, Ferner RE. Dose omissions in hospitalized patients in a UK hospital. Drug safety. 2012;35:677-83.

2. Blignaut AJ, Coetzee SK, Klopper HC, Ellis SM. Medication administration errors and related deviations from safe practice: an observational study. Journal of clinical nursing. 2017;26:3610-23

3. Munzner E, Welch SA and Richardson KL. Measuring and describing dose omissions using an electronic medication management system. Journal of Pharmacy Practice and Research. 2012;42:264-7.

4. Lamerton AB, Morris F, Mann F, Harper L, Ashcroft DM. Evaluation of pharmacy Technician supported Medication administration rounds (TECHMED) on reducing omitted doses: a pilot randomised controlled trial and process evaluation in a university teaching hospital; 2017.

5. Grissinger MC. Omission of high-alert medications: a hidden danger. AJN the American Journal of Nursing. 2017;117:66-70.

6. Poder TG, Maltais S. Systemic analysis of medication administration omission errors in a tertiary-care hospital in Quebec. Health Information Management Journal. 2020;49:99-107.

7. Kalisch BJ, Xie, B. Errors of omission: missed nursing care. Western journal of nursing research. 2014;36 875-90.

8. Powell N, Franklin BD, Jacklin A, Wilcock M. Omitted doses as an unintended consequence of a hospital restricted antibacterial system: a retrospective observational study. Journal of Antimicrobial Chemotherapy. 2015;70:3379-83.

9. Kampamba M, Abanur F, Hikaambo CN, Mudenda S, Saini K, Kaonga P. Effects of medication knowledge on medication adherence among hypertensive patients at Matero level one hospital, Lusaka city, Zambia: a cross sectional study. Int J Basic Clin Pharmacol 2021a;10:893-9.

10. Shandilya S, Khwaja Nizamuddin MWF, Noor S, Abraham S. Omitted medications: a continuing problem. Clinical Medicine. 2015;15:12.

11. Green C, Du-Pre P, Elahi N, Dunckley P, McIntyre A. Omission after admission: failure in prescribed 
medications being given to inpatients. Clinical medicine. 2009; 9: 515.

12. Mueller BU, Neuspiel DR, Fisher ERS. Principles of pediatric patient safety: reducing harm due to medical care. Paediatrics. 2019;143.

13. Benjamin L, Frush K, Shaw K, Shook JE, Snow SK, Medicine A, et al. Pediatric medication safety in the emergency department. Paediatrics. 2018; 141.

14. Sutherland A, Phipps DL, Tomlin S, Ashcroft DM. Mapping the prevalence and nature of drug-related problems among hospitalised children in the United Kingdom: a systematic review. BMC paediatrics. 2019;19:1-14.

15. Carpenter D, Gonzalez D, Retsch-Bogart G, Sleath B and Wilfond B. Methodological and ethical issues in pediatric medication safety research. Paediatrics. $2017 ; 140$.

16. Kampamba M, Demba F, Mudenda S, Mufwambi W, Zingani E, Chabala, et al. Medication administration omission errors: Frequency and their causes during medication administration process at Ndola Teaching Hospital in Zambia. African Journal of Pharmacy and Pharmacology. 2021b;15:174-82.

17. Ahmed T, Haq N, Ammar M, Waqas M, Minhas M. Assessment of inpatients omission errors made by nurses throughout the medication administration process. MOJ Toxicology. 2018;4:242-5.

18. Keers RN, Williams SD, Cooke J, Ashcroft DM. Prevalence and nature of medication administration errors in health care settings: a systematic review of direct observational evidence. Annals of Pharmacotherapy. 2013;47:237-56.

19. Fekadu G, Oljira A, Geda B and Egata G. Unsafe medication administration experience in nursing practice at Public Hospitals of Harari region, eastern Ethiopia: Phenomenological Study.2010.

20. Feleke Yemisirach and Girma Biniyam. Medication Administration Errors Involving Paediatric InPatients in a Hospital in Ethiopia. Tropical Journal of Pharmaceutical Research. 2010; 9.

21. Assiri GA, Shebl NA, Mahmoud MA, Aloudah N, Grant E, Aljadhey H, Sheikh A. What is the epidemiology of medication errors, error-related adverse events and risk factors for errors in adults managed in community care contexts? A systematic review of the international literature. BMJ Open. 2018;8:e019101.

22. Rasool MF, Ur Rehman A, Imran I, Abbas S, Shah S, Abbas G, et al. Risk Factors Associated With
Medication Errors Among Patients Suffering From Chronic Disorders. Frontiers in public health. 2020;8.

23. Rostami P, Heal C, Harrison A, Parry G, Ashcroft DM, Tully MP. Prevalence, nature and risk factors for medication administration omissions in English NHS hospital inpatients: a retrospective multicentre study using Medication Safety Thermometer data. BMJ Open. 2019;9:e028170

24. Ross LM, Wallace J, Paton JY. Medication errors in a paediatric teaching hospital in the UK: five years operational experience archives of Disease in Childhood 2000;83:492-7.

25. Kampamba M, Mwanza T, Saini K, Hatwiko H, Biete L, Hikaambo CN. Wrong time medication administration errors: Frequency and their causes at Adult University Teaching Hospitals in Zambia. African Journal of Pharmacy and Pharmacology. 2020;14:362-9.

26. Miller MR, Robinson KA, Lubomski LH, Rinke ML, $\&$ Pronovost PJ. Medication errors in paediatric care: a systematic review of epidemiology and an evaluation of evidence supporting reduction strategy recommendations. Quality \& safety in health care. 2007;16(2):116-26.

27. Oshikoya KA, Oreagba IA, Ogunleye O, Senbanjo I, Macebong G, Olayemi S. Medication administration errors among paediatric nurses in Lagos public hospitals: an opinion survey. International journal of risk \& safety in medicine. 2013; 25:67-78.

28. Lawler C, Welch SA, Brien J. Omitted medication doses: frequency and severity. Journal of Pharmacy Practice and Research. 2004; 34:174-7.

29. Kandil M, Sayyed T, Emarh M, Ellakwa H, Masood A. Medication errors in the obstetrics emergency ward in a low resource setting. The Journal of Maternal-Fetal \& Neonatal Medicine. 2012;25:137982.

30. Berdot S, Sabatier B, Gillaizeau F, Caruba T, Prognon P, Durieux P. Evaluation of drug administration errors in a teaching hospital. BMC health services research, 2012;12:1-8.

Cite this article as: Kampamba M, Mulolo S, Phiri M, Chulu MC, Mufwambi W, Mudenda S, et al. Medication omissions in the first 48 hours after admission: failure in prescribed medicines reaching in-patients in paediatrics wards at the University Teaching Hospitals, Children's Hospital in Lusaka, Zambia. Int J Basic Clin Pharmacol 2021;10:1324-9. 